\title{
The secret to longevity and sustainable environmental development
}

\author{
Batnairamdal Chuluun ${ }^{1 *}$, Alexandrina Vodenitcharova $^{2}$, Todor Kundurzhiev ${ }^{3}$, Todor \\ Krasimirov Dimitrov ${ }^{4}$, Alexandra Trajkovska ${ }^{4}$, and Ariunsanaa Byambaa ${ }^{4}$ \\ ${ }^{1}$ International School of Mongolian Medicine, Mongolian National University of Medical Sciences, \\ S.Zorig street,Ulaanbaatar 14210, Mongolia \\ ${ }^{2}$ Mongolian University of Pharmaceutical Sciences, S.Zorig street,Ulaanbaatar 14210, Mongolia \\ ${ }^{3}$ Education affairs at the Faculty of Public health, Medical University- Sofia, Bialo more 8 str., Sofia, \\ 1527, Bulgaria \\ ${ }^{4}$ Public Health, Medical University- Sofia, 1527, str. Bialo more â,,- 8, Sofia, Bulgaria
}

\begin{abstract}
Studying dietary practice and lifestyle of Mongolian monks. The research is supported by Zuun Khuree Dashichoiling Monastery. We used historical classification, conclusion and review listing methods, analysis, integration, methods of evidential documents and linguistic study in order to conduct the research. Venerable monks were head educators in social life and example of healthy life by fasting and prohibiting meal after dusk. The five elements of human body and evolution three elements were continuously changed in order to adapt environmental and climate changes. Monks used to manage their diet by knowing accumulation, activation and pacification of elements and six seasons. They live long with clear minds free from senility, opaqueness, which directly related to their proper diet and intellectual exercises. Aging is not obsolescence but a normal phenomenon of healthy body. In theory of the traditional medicine, biological age of may be related to the percentage of wind, bile and phlegm. It is possible to prevent and heal diseases through proper use of diet by coordinating with body features, age requirements and seasonal differences. By combining theory of traditional medicine and right lifestyle, there are ways for creating new preventive treatment methods.
\end{abstract}

\section{Introduction}

In order to study diets of Mongolian monks, we need to deep dive into multiple aspects of history such as what was Mongols' religion, when and from where the Buddhism was introduced in Mongolia and how Mongols accepted. Activities and formalities of Buddhism have enriched with customs and historical tradition of Mongols to adapt its soil. This time, we have chosen following topic for the purpose of clarifying dietary and lifestyle of monks. Pilgrimage and ritual practice of monks becomes good exercise for movement. According to theory of the traditional medicine, biological age of a person may related to the percentage

*Corresponding author: dem.olga@mail.ru 
of "gas, jaundice and stomach cancer", which are the primary universal quality of organ systems, possible to be preserved in all parts of living body.Lactic acid bacteria (LAB) have been widely studied and used worldwide for their health benefits. LAB species are a very important resource in the dairy industry for manufacturing cheese and fermented milk products.

Yogurt is a popular dairy product with widespread worldwide consumption. Studies have reported health benefits of yogurt owing to its probiotic content comprising live LAB that prevent pathogen growth, by producing organic acids and bacteriocins in the gastrointestinal tract $[1,2]$. Yogurt helps reduce blood cholesterol, eliminate endotoxins, and assimilate vitamins and minerals and enhance digestive functions including nutrient and lactose absorption. Additionally, yogurt helps prevent colorectal cancer and diabetes and helps prevent and manage hyperlipidemia [3]. Furthermore, yogurt contains various LAB and stimulates the immune system and stabilizes the gut microflora $[4,5]$. Consequently, yogurt rich in probiotics has attracted increasing attention $[6,7]$.

Obesity is a serious public health concern, characterized by excessive accumulation of body fat, resulting in an increase in body weight and leading to metabolic and chronic disorders such as diabetes, hypertension, arteriosclerosis, insulin resistance, and cardiovascular diseases [8-10]. The World Health Organization (WHO) has reported the environmental, genetic, and neuroendocrine factors associated with obesity, along with infectious agents $[11,12]$. The bacteria commonly present in the human gut regulate energy and nutrient absorption differently in obese and lean individuals, suggesting that the gut microbiota play an important role in the pathogenesis of obesity [13]. Treatment of obesity with a probiotic-rich diet is a major advancement in the treatment of obesity [14].

In the past decade, Mongolian dairy products have been consumed as not only energy sources but also traditional medicines [14]. Mongolian traditional fermented milk products vary in accordance with their source of milk: airag (horse), hoormog (camel), undaa (cow), and tarag (yaks or cattle). Several studies have investigated the microbial content and the diversity of LAB in Mongolian dairy products [15-19]. L. fermentum is a heterofermentation LAB belonging to family Lactobacillaceae, phylum Firmicutes. LAB are generally recognized as safe (GRAS) microbes and widely used in the production of fermented food products. L. fermentum is considered a potential probiotic organism because of its desirable probiotic characteristics including its beneficial effects on immune function, nonpathogenicity, and being a part of the natural internal environment of humans [20]. However, few studies have focused on the functional and metabolic aspects of yogurt in animal models. Therefore, the potential effects of these products are unknown [21].

Obsolescence negative process of living tissue development and cause deficiency of body by affected by internal and external damaging factors of human body until the end of life from the time of birth. Matter of long living and obsolescence was discussed at World first science meeting in 1938 when they introduced the possibilities of human being to live up to 150 year or more. The main purpose of human life is living longer as its key is healthy lifestyle [22].

We aim to studying dietary practice of Mongolian monks. Within then of the above purpose; 1.It is clarifying and identifying types of dietary; 2.Coordinate with season, and life conditions; 3.Explanation regarding to the aging.

\section{Materials and methods}

Theresearch is supported by Zuun Khuree Dashichoiling Monastery. We used historical classification method, analysis, integration, conclusion method, review listing methods of evidential documents and linguistic study in order to conduct the research. 


\section{Results}

1. Food and drinks reach in stomach after swallowed via throat by holding gas, dissolved in stomach by stomach cancer, melted by digestive jaundice, then separate liquids and solids with stomach fire gas. Such solids become liquid or solid excrements while liquids further develop 7 body strengths step by step. Such liquid is called refreshment liquid. The refreshment liquid develops with 3 digestive energy especially digestive jaundice for further digestion. The liquid flows in liquid transfer artery from stomach to liver, where it transform to blood [23]. Food and drink means food items that develops 3 elements and 7 body strengths containing the nutrition necessary for human body. In the Four Roots of Medicine, food is classified in 5 categories such as "seeds, meat, oil vegetables, and cooked food" while drink classified as "milk, water and alcohol".In Real book of food and drink, food classified in to 7 categories of semolina, flesh of wild animal and birds, fish, fruits, and oil while drink referred in 4 categories of "milk, water, alcohol and tea"[24].Tastes, power and benefits of food and drinks: Foods and drinks are considered as a type of medicine. In other word, there are no margin between medicine and food or drinks as they have 6 tastes, 8 powers and 17 benefits like medicine. With this regard, the Four Roots of Medicines taught that "If one knows the tastes and quality of any substance, one can use them as medicine with proper ingredients because the all the substances in the world originate from 5 elements and be 6 tastes. [25]. Even though, tastes, power and benefits of food or drinks and medicine similar, they cannot substitute each other because people should not desert with foods and drinks as they support and develop human body every day. If anyone wishes to be healthy without overeating, undereating and avoiding wrong diet, he or she should learn the tastes, power and benefits of foods and drinks in order to balance three elements [26].It is very significant for human to use proper taste, quality and amount of foods and tastes. The food and drink must support and balance the 3 elements of human body. The seven strengths depend on the 3 elements in order to balance them. If one consumes equal proportion of diet, it will keep functions of five vital organs, six vessel organs without activating 3 harms [27].Adopting amount of diet -It is taught that $/ 2 / 1 /$ one third of stomach shall be filled with food, another one portion is filled with drink while remaining one shall be empty. Moreover, overeating without satisfaction would cause stomach weakness and digestive disorders. It is taught nonvegetarian food and heavy food shall be consumed in half of stomach while allowing vegetarian foods in full scale of stomach [28]. Adopting time of diet - it is recommended to take meal on fixed hours. Eating 3 times a day will develop body. Drinking tea and having light meal every morning good for suppressing gas and nourishing nerve system. Taking hyaram - boiled milk diluted with water, milk tea, watery rice broth boiled in water, honey water, boiled water, and water in silver cup for hours for your body features in the morning hours will eliminate stomach cancer mucous and brighten appearance. It is ideal to have food difficult to digest and majority of meal for lunch. It is recommended to eat light meal for dinner and not consume heavy diet after 6 o'clock in the evening [29].Making 1-2 days in weekly diet menu balances stomach functions and improves body strengths. Food shall be well chewed in a peaceful manner and only consume next meal after well digestion. Overeating and frequent use of nutritious meal difficult to digest exhausts stomach strength and cause stomach problem. Consuming meal with poor nutrition in small amount causes weight loss and exhausts strength for sickness [30]. 


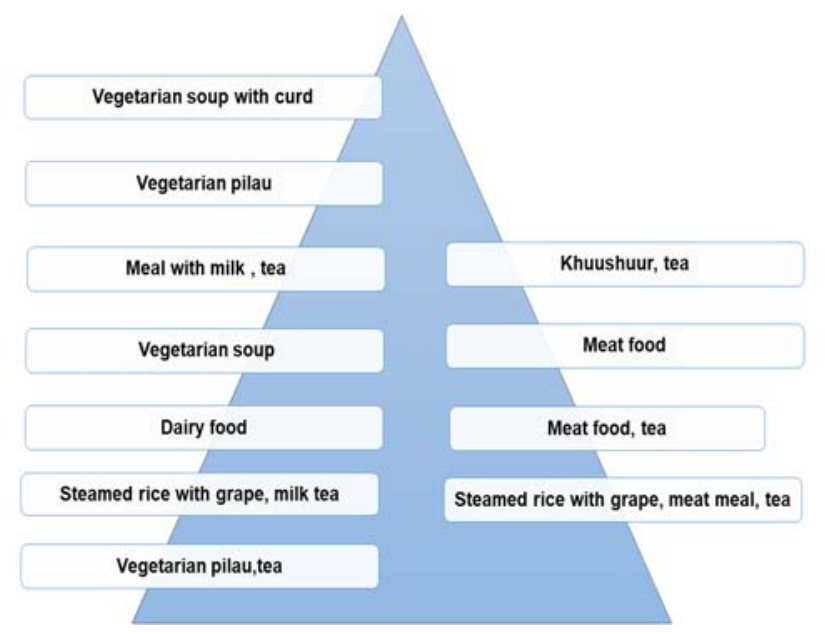

Fig. 1. Results of identifying types of dietary.

2. It is highly recommended to adopt your lifestyle and diet habit to depend on changes of body functions according to four season's changes as taught in theoretical root. Otherwise, it will cause diseases. Mongols used to divide one year into 6 months such as first month of winter, last month of winter, spring, balance or blossom, summer and autumn. They used to adopt their diet for the seasons [31].Summer season continues from VI/16 - VIII/15 of lunar calendar, when accumulated gas INS spring activated in summer time due to raining coolness to correct soft essence. Blood circulation accelerate, fine hairs of the body rise and open up skin pores allowing your body energy going out causing degradation of stomach operation. In this season, monks used to camp countryside for dairy products such as fermented mare's milk-airag, milk, yogurt, water with old honey, airag, alcohol, cream, and curd refraining to kill animals [32].Autumn season continues from VIII/16 - X/15 of lunar calendar, when jaundice fever active. Therefore, they use to consume diet with chilly properties, tasty, bitter, sour taste, boiled water, cold spring water as drink and in autumn, Khailan congregation happen requiring monks meal only midday between 11:40am to 01:40pm so called Hour of horse by avoiding to exposure of fire and sunlight for precepts.First month of winter continued from X/16 - XII/15, when one may allowed to eat warm diet with tasty, sour, salty to fill your stomach as power is strong to digest food well when body heat reaches its peak and all pores of skins closed along with bending fine hairs of human body. Furthermore, they used more of flour with milk in vegetarian foods and use milk as drink.Last month of winter continues from XII/16 - II/15 when people used to drink tea with oil, milk, barley flour, ginger, red pepper, dried wild leek, wild onion, ramson, garlic, onion and drink steamed soup[33].Spring season covers II/16 - IV/15 when accumulated stomach cancer in winter start to active in warm spring, so vomiting treatment works in order to cleanse stomach. This period requires active body movement voiding to sleep day time by eating flesh, fat, oil of land animal, drink soup with curd, barley flour with oil, buuz /steamed dumpling/, bansh /boiled dumpling/ with garlic, khuushuur /fried dumpling/, ginger soup, boiled water, honey drink, tea flavored with oil. Moreover, eating flesh of goat that pasture spring pasqueflower help balancing blood pressure of people who have anaemia by refreshing strength[32].Blossom /balance/ period continues from IV/16 - VI/15.It was recommended to consume tasty, light, chilly diet refraining from salty and sour foods and drink yogurt and milk.

3. Monks follow strict diet when it comes to having foods and drinking, they drink larch bark extract with bitter salt in order to dilute blood without regard to season and uses sheep tail fat regularly in order to prevent from arteriosclerosis. With research, we found there are 
7 different meals including Tsogchid offering, Non vegetarian soup, vegetarian soup, steamed rice with grape, tea, vegetarian soup with milk, vegetable pilau, vegetarian soup with curd, buuz, and khuushuur and 3 types of drink. Although food and drink essential for human body, it may cause health problem if applied improper way. Spoiled or sting meat, vegetables, water may cause other various diseases and fatal cancer, as no meals shall be overnight and overcooked in terms of realizing the impermanency.

\begin{tabular}{|c|c|}
\hline $\begin{array}{l}\text { VI/16 - VIII/15 } \\
\text { Summer }\end{array}$ & $\begin{array}{l}\text { - dairy products, kumiss, mare's milk, milk, yogurt, } \\
\text { cream, dried curds }\end{array}$ \\
\hline $\begin{array}{c}\text { VIII } / 16-\mathrm{X} / 15 \\
\text { Autumn }\end{array}$ & $\begin{array}{l}\text { - one meal in midday between 11:40am to } \\
01: 40 \mathrm{pm} \text { so called Hour of horse }\end{array}$ \\
\hline $\begin{array}{l}\text { X/16 - XII/15 } \\
\text { First month of winter }\end{array}$ & - meat food, flour with milk in vegetarian foods \\
\hline $\begin{array}{l}\mathrm{XII} / 16-\mathrm{II} / 15 \\
\text { Last month of winter }\end{array}$ & $\begin{array}{l}\text { - tea with clarified butter , milk, barley flour, } \\
\text { ginger, red pepper, dried wild leek, wild onion, } \\
\text { ramson, garlic, onion and drink steamed soup }\end{array}$ \\
\hline $\begin{array}{l}\text { II/16 - IV } / 15 \\
\text { Spring }\end{array}$ & $\begin{array}{l}\text { - eating flesh, fat, oil of land animal, drink soup } \\
\text { with curd, barley flour with oil, buuz /steamed } \\
\text { dumpling/, bansh /boiled dumpling/ with garlic, } \\
\text { khuushuur /fried dumpling/, ginger soup, boiled } \\
\text { water, honey drink, tea flavored with oil }\end{array}$ \\
\hline $\begin{array}{l}\text { IV } / 16-\text { VI } / 15 \\
\text { Blossom }\end{array}$ & $\begin{array}{l}\text { - consume tasty, light, chilly diet refraining from } \\
\text { salty and sour foods and drink yogurt and milk }\end{array}$ \\
\hline
\end{tabular}

Fig. 2. Types of meals per season.

\section{Discussion}

Let's talk about benefits of wheat, beans, meat as food and milk of animals and water drinks used by Mongol monks. Although milk components of animals vary, their size and ingredients are different. This depends on structure livestock pasture, water and biological features. Milk was not only used for dietary consumption, but also applied as medical mineral water in order to heal various diseases. Consumption of dairy products keeps human body healthy and used as perfect tool for preventing diseases eliminating unfavorable environment. Goat milk is used for healing liver and kidney inflammation, while female camel's milk and mare's milk are good for antiscorbutic purpose [24].

Cow milk

Cow milk- beneficial for lung problem, chronic lung diseases, chronic typhoid, and diabetes. It sharpens mind. Yak milk contradicts with stomach cancer and jaundice. 
Mare's milk

One feature of mare's milk is low dry agents, oil, protein, and mineral but also 1.5-4 times greater lactose than other livestock. Fermented mare's milk (airag) is good for healing TB and some gastrointestinal diseases, improves body metabolism and treating lung diseases. Airag almost contains all vitamins necessary for human body [17].

Female camel'smilk

Oil of female camel's milk fluctuates during milking season and oil content decreases in summer hot and increases in cool season.

Sheep milk

Sheep milk affects heart even it pacifies gas. Sheep milk is sour, highly dense, 1.5 times greater than dry agent compared to cow milk, rich with protein, oil, mineral, vitamin, ferment, lecithin and sterol, and its casein is denser than cow milk creating curd [19].

Goatmilk

Goat milk helps holding breath. Consumption period is from June 01 to August 15. Dry agent of milk protein essence reaches $28.3 \%$ containing majority of oil and protein. Each day passes, amount of protein, oil and mineral decreases gradually while lactose gradually increases. Protein essence of goat milk has globulin amount 20 times greater than normal milk and 2 time's greater albumin exist playing important role in order to protect the offspring from any diseases [27].

Yogurt

It is made from milk of sheep, goat, cattle, and yak. The main representative of lactose acid microorganisms in Mongolian yogurt ferment Lactobacillus deibrueckiisubd. bulgaricus, Streptococcus thermophilus, , Lactobacillusand Bifidobacterium. Dairy products fermented by L. fermentum TSI, isolated from Mongolian traditional dairy products, may be a functional probiotic in improving blood cholesterol and body fat accumulation [29].

Water

Rain water, snow water, spring water are the best sort of water while river water, well water, salty water and tree water are not the good ones.

Water with strong flow from Snow Mountain - Poor digestion if drink cold;

Backwater -worm diseases, stomach cancer cause and bad for cardiac diseases;

Cold clean water -helps for dizziness, hangover, feeling dim, vomiting, thirsting, feeling fever, bleeding, jaundice, and poisoning; and

Boiled water -good for calorie recovery, food digestion, stopping hiccupping, abdomen swallow by stomach cancer and gas, uneasiness of breathing and new typhoid.

From ancient time, Mongols used to fry and mill cleaned seed of barley to make sifted flourand used pearl barley in their diet widely. Moreover, they used rye flour to make bread products, millet for fried grain for daily consumption. Wheat flour has major role in food consumption of Mongols. The wheat flour is used as meal ingredients along with meat and milk but also to make various confectioneries, pastries, and croissants. Mongolian pastries are ideal feature food for camping, and nomad life for long term preservation at original qualityas they are well kneaded for compression, and fried in abundant fat oil, which is very nutritious [26]. Mutton has good quality and taste, which related to its delicate and fine texture. Most optimal ratio of bones, fat and meat is 1:5 that frequently occur with two years old sheep. Complete usage of internal flesh of sheep may related to their protein content. Percentage of Mongolian sheep's non-substituting vitamin is 41.64 while mutton of Kyrgyz fine-fleeced sheep achieved 29.28 and meat of New Zealand sheep is 39.09.Beef is likely cool nature meat while yak meal is warm nature meat. Non-substituting vitamin in beef is comparatively higher and protein in only $50 \mathrm{~g}$ of dried meat cam keep human need for a whole day. Fat-soluble vitamins dominates in beef. 
Dried meat: The best way to keep livestock meat for longer time is drying. The dried meat can be made by mutton, beef, camel meat, and goat meat. Ideal temperature for drying is at least minus 10 degree Celsius mostly the end of November and beginning of December cold. Flesh shall be chopped with thickness of 2-4 centimeters and 15-30 centimeter long hanged on stretched rope in a forking manner with 2 centimeters of intervals. Dried beef and camel meat are better in quality. Dried meat prepared in Mongolian way does not lose its quality for 1-3 years. It is significant as it is 4 times lighter than meat with bones, feasible for transporting and storing for its volume, beneficial for the growth of herd, and it is much beneficial in terms of economy and health. Scientists discovered that around 80 percent of dried meat is protein, which contains rich vitamins and nutrition [28].

\section{Conclusions}

1. Number and choice of monk's diet us limited as they obey strict rules of refraining from unfavourable meals.

2. It demonstrated that consuming diets coordinating with weather and 6 seasons are important for long and healthy life.

3. It is recommended to use more unsaturated fat acid, protein, tail fat, and nut in order to prevent from senility, opaquenessas one get older, body parameters decrease and vein stiffness.

\section{References}

1. P.Bourlioux, B.Koletzko, F. Guarner, V. Braesco, Am. J. Clin. Nutr. 78, 675-683 (2003)

2. G.Mazza, Functional Food, Biochemical and Processing Aspects; Taylo and Francis, GP. LLC. Roca Raton, FL, USA 357-374 (1998)

3. Y.H. Cho, H.J. Shin, C.H. Chang, M.S.Nam, Korean J. Food Sci. Anim. Resour, 26, 257 (2006)

4. R.Axelsson, Lactic Acid Bacteria: Microbiology and Functional Aspects; S. Salminen, von Wright, A., Eds.; Marcel Dekker Inc.: New York, NY, USA 53 (1998)

5. S. Parvez, K.A. Malik, S.A. Kang, H.Y.Kim, J. Appl. Microbiol 100, 1171 (2006)

6. D.I. Pereira, G.R.Gibson, Crit. Rev. Biochem. Mol. Biol., 37, 259 (2002)

7. A. Usman, J. Dairy Sci. 83, 1703 (2000)

8. I.Wickelgren, Science 280, 1364 (1998)

9. D.W. Haslam, W.P. James, Obesity. Lancet 366, 1209 (2005)

10. D. Jin, Y. Xu, X. Mei, Q. Meng, Y.Gao, B. Li, Y. Tu, J. Funct. Foods 5, 1142 (2013)

11. H. Tilg, A.R. Moschen, A.Kaser, Obesity and the microbiota. Gastroenterology 136, 1476 (2009)

12. N.V. Dhurandhar, Lancet Infect. Dis. 11, 963-969(2011)

13. J.K. DiBaise, H.Zhang, M.D.Crowell, R.Krajmalnik-Brown, G.A.Decker, B.E. Rittmann, Mayo Clin. Proc. 83, 460-469(2008)

14. K. Watanabe, Jpn. J. Lact. Acid Bact. 22, 153-161(2011)

15. K.Uchida, M.Hirata, H.Motoshima, T.Urashima, I. Arai, Anim. Sci. J. 78, 650-658 (2007)

16. K.Watanabe, J.Fujimoto, M.Sasamoto, J.Dugersuren, T.Tumursuh, S.Demberel, World J. Microbiol. Biotechnol., 24, 1313-1325 (2008) 
17. M.Miyamoto, Y.Seto, H.Nakajima, S.Burenjargal, A.Gombojav, S.Demberel, T. Miyamoto, Food Sci. Technol. Res., 16, 319-326 (2010)

18. S.Takeda, K.Yamasaki, M.Takeshita, Y.Kikuchi, C.Tsend-Ayush, B.Dashnayam, A.M. Ahhmed, S.Kawahara, M.Muguruma, Anim. Sci. J., 82, 571-579 (2011)

19. J.Yu, W.H.Wang, B.L.Menghe, M.T.Jiri, H.M.Wang, W.J.Liu, Q.H.Bao, Q.Lu, J.C. Zhang, F.Wang, et al, J. Dairy Sci. 94, 3229-3241 (2011)

20. M.Mikelsaar, M. Zilmer, Microb. Ecol. Health Dis.21, 1-27 (2009)

21. V.I.Vernadskii, Biological Role of Microelements (Moscow, 1983)

22. D. Harvey, Analytical chemistry, 547-548 (2006)

23. G.Gombo. Tradition and Change in Mongolian diets (Ulaanbaatar: MUST Publishing House 98, 2005)

24. L.Lkhagvaa, Chemical ingredients and nutrition of food products (Ulaanbaatar, 25, 2003)

25. Ts,Batsukh, D.Nansalmaa, Ch.Ulziiburen. Formula foods (Ulaanbaatar, 25-26,2003)

26. Dh.Luvsanchoidog, Teaching Title Light to dispel the darkness (People's Publishing Committee of Inner Mongolia Autonomous Region,People's Republic of China, Huhhot 69-74, 1998)

27. B.Dagvatseren, U.Batchimeg, T.S.Varlamova, G. Narantsetseg. Traditional medical method for preventing diseases (Ulaanbaatar, 110-111, 2020) 